\title{
SABERES DOCENTES NA FORMAÇÃo INICIAL DE PROFESSORES DE BIOLOGIA
}

\author{
TEACHER'S KNOWLEDGE IN THE INITIAL TRAINING OF BIOLOGY TEACHER
}

DOI: http://dx.doi.org/10.23926/RPD.2526-2149.2019.v4.n2.p669-684.id515

\section{Hiléia Monteiro Maciel Cabral \\ Doutoranda em Ensino de \\ Ciências e Matemática \\ (REAMEC/UFMT) \\ Professora da Universidade \\ do Estado do Amazonas \\ (UEA) \\ hileiamaciel@gmail.com}

\section{Cirlande Cabral da \\ Silva}

Pós doutorado em Educação

em Ciências (UFSM)

Professor do Instituto

Federal do Amazonas

(IFAM)

cirlandecabral@gmail.com

\section{Cleusa Suzana}

Oliveira de Araujo

Doutorado em Biologia pelo (INPA)

Professora da Universidade do Estado do Amazonas

(UEA)

cleusasuzana.araujo@gmail. com
Resumo: Os saberes docentes são determinantes na atividade do professor. Diversos autores evidenciam os conhecimentos considerados necessários ao professor para saber ensinar, o que nos remete a uma formação inicial contextualizada e fundamentada, em que a prática pedagógica constitui ponto de partida para a compreensão dos fenômenos que ali se apresentam. O objetivo dessa pesquisa foi compreender quais saberes docentes estão presentes nos licenciandos do curso de Ciências Biológicas da Universidade do Estado do Amazonas. Como metodologia de análise dos dados, utilizamos a análise de conteúdo de Bardin. A coleta de dados foi realizada a partir de um questionário com 20 licenciandos do curso de Ciências Biológicas. Os resultados desta pesquisa revelam a presença da identidade docente, os saberes experienciais e o processo de formação profissional. Dessa forma, a construção do conhecimento é o resultado do conjunto de etapas, que ocorre a todo momento durante a formação do professor.

Palavras-chave: Saberes Docente; Formação Inicial; Biologia.

Abstract: Teaching knowledge is a determining factor in teacher activity. Several authors highlight the knowledge considered necessary for the teacher to know how to teach, which brings us back to an initial contextualized and grounded formation, in which the pedagogical practice is the starting point for understanding the phenomena that are presented there. The objective of this research was to understand which teaching knowledge is present in the licenciandos of the course of Biological Sciences of the University of the State of Amazonas. As a methodology for data analysis, we used Bardin's content analysis. The data collection was carried out from a questionnaire with 20 licenciandos of the course of Biological Sciences. The results of this research reveal the presence of the teaching identity, the experiential knowledge and the professional training process. In this way, the construction of knowledge is the result of the set of steps, which occurs at all times during teacher education.

Keywords: Knowing Teacher; Initial formation; Biology. 


\section{INTRODUÇÃO}

Os saberes docentes são determinantes na atividade do professor, principalmente como resultado na aprendizagem dos alunos e consequentemente no sucesso escolar. Diversos autores [(Tardif (2002); Gariglio; Burnier, 2014; Severino (2009); Gauthier, 2013)] evidenciam os conhecimentos considerados necessários ao professor para saber ensinar, o que nos remete a uma formação inicial contextualizada e fundamentada, em que a prática pedagógica constitui ponto de partida para a compreensão dos fenômenos que ali se apresentam.

Nessa perspectiva, Altet (2001) afirma que a principal função da atividade docente é o ensino, que consiste em um processo intencional e interpessoal, que desenvolve essencialmente a comunicação verbal e o discurso dialógico, sendo esses utilizados como meios para favorecer, provocar e propiciar a aprendizagem em uma dada situação ou contexto.

Concordamos com Nunes (2001) quando afirma que as pesquisas sobre formação e profissão docente apontam para uma revisão da compreensão da prática pedagógica do professor, que é tomado como mobilizador de saberes profissionais. Considera-se, assim, que este, em sua trajetória, constrói e reconstrói seus conhecimentos conforme a necessidade de utilização dos mesmos, suas experiências, seus percursos formativos e profissionais.

Na esteira desse pensamento, percebemos que a formação inicial do professor é alvo de muitas discussões, principalmente no que se refere à prática pedagógica, pois é fundamental para o processo de ensino e aprendizagem e, consequentemente, para o sucesso escolar. Assim, acreditamos que uma nova forma de ver a educação e a formação de professores passa, necessariamente, por uma compreensão de mundo, das mudanças do contexto escolar, da implantação das novas tecnologias da informação, da integração escolar entre pessoas diferentes e por que não dizer também, do respeito ao próximo.

As experiências pedagógicas deveriam buscar novas alternativas para a aprendizagem, um ensino mais participativo, mais cooperativo, mais dialógico e menos individualista. Desta maneira, podemos dizer que tudo isso implica uma nova maneira de ver a formação docente.

Concordamos com Imbernón (2010) quando afirma que essa nova formação deveria partir não apenas do ponto de vista dos especialistas, mas também da grande contribuição da reflexão prático-teórica que os professores realizam sobre seu próprio saber. Quem melhor pode realizar uma análise da realidade, uma compreensão, interpretação e intervenção sobre esta, do que o próprio professor? As instituições educacionais devem ser o foco da formação de professores, os sujeitos ativos e protagonistas da mesma (IMBERNÓN, 2010). 
Portanto, refletir sobre aquilo que foi vivido no ambiente escolar, na dinâmica do processo e, consequentemente buscar fundamentação teórica para essa prática permite ao professor e ao educando um movimento dialético de construção do conhecimento acerca de si mesmo e de sua ação, que corrobora na elaboração de questionamentos e de dúvidas que fertilizarão esse novo fazer com um novo olhar.

Tardif (2014, p. 21) ressalta a importância dos saberes no papel reflexivo do professor em seu ambiente de trabalho, visto que "[...] ensinar é mobilizar uma ampla variedade de saberes, reutilizando-os no trabalho para adaptá-los e transformá-los pelo e para o trabalho", sendo essa reutilização impraticável sem os movimentos reflexivos do professor em relação aos seus saberes e ao contexto educacional no qual ele está inserido. Sendo assim, pensar nos saberes sobre estes dois elementos constitutivos, trabalho e prática reflexiva, é considerar que os saberes docentes possuem um lugar e que este lugar se encontra na relação entre esses dois elementos.

Compartilhamos as crenças de Demo (1998) quando este desafia os professores a assumirem a pesquisa como atividade cotidiana, onde o questionamento reconstrutivo ganha espaço em sala de aula. Significa dizer que o espaço pedagógico da sala de aula precisa ganhar vida, ser redimensionado para reconstruir-se em um lugar onde educador e educandos possam refletir, discutir, reconstruir seus saberes, gerar aprendizagens significativas.

Alicerçado nessa discussão, o objetivo dessa pesquisa foi compreender quais saberes docentes estão presentes nos licenciandos que estão concluindo o curso de Ciências Biológicas da Universidade do Estado do Amazonas(UEA)/ Manaus.

\section{OS SABERES E A FORMAÇÃO INICIAL DE PROFESSORES}

A formação de professores, tanto inicial quanto continuada, é um campo da pesquisa educativa em constante expansão. Existe consenso entre muitos autores de que investir na qualificação desta formação é uma das formas eficientes de atingir melhorias no processo de ensino e de aprendizagem escolar (PORLÁN; RIVERO, 1998; ZEICHNER, 1987). Na literatura relacionada com Educação em Ciências, há inúmeros trabalhos de investigação sobre processos de formação docente, especialmente no Brasil (MALDANER, 2006; SCHNETZLER, 2000; ROSA, 2004; CARVALHO; GIL- PÉREZ, 1995; PIMENTA, 1999; PIMENTA; LIMA, 2004), entre outros, que se referem à formação do professor pesquisador, processos reflexivos, saberes da prática, saberes docentes, etc. 
Para Brito (2007) na formação do professor, seja para a educação básica, seja para a universidade, é imprescindível que os profissionais da educação produzam saberes que os tornem cada vez mais competentes e ativos no processo de ensino-aprendizagem.

Acreditamos que é necessário para o professor compreender a importância dos saberes docentes para a melhoria de sua prática em sala de aula, pois a dinâmica de transformação da sociedade é extremamente rápida, com novos conhecimentos surgindo a todo instante. Em função disso, faz-se necessário que o professor tenha domínio desses saberes docentes para que possa contribuir para a preparação do discente para atuar numa sociedade em constante transformação. Diversas pesquisas mostram a importância do docente na formação do aluno, pois o mesmo é disseminador de ideias e valores, e não apenas de conteúdos, muito mais do que qualquer profissional em outra área de atuação.

Concordamos com Nóvoa (1992, p. 25) quando afirma que a formação do professor deve ser vista numa perspectiva crítico-reflexiva que possibilite aos docentes a construção de sua autonomia pessoal e pedagógica, a qual "não se constrói apenas por acumulação de cursos, de conhecimentos ou de técnicas, mas sim, por meio do trabalho de reflexividade crítica sobre as práticas e da (re) construção permanente de uma identidade pessoal".

Portanto, discutir a formação de professores é fundamental para que a profissão seja entendida de acordo com a sua complexidade, tanto na prática pedagógica quanto no contexto de atuação desses professores. No âmbito das pesquisas, observa-se que esta formação envolve os elementos da vivência escolar, o período acadêmico, o desenvolvimento pessoal e profissional da atividade docente. É a partir desses elementos que é constituída e modificada a identidade profissional, pois os professores, em geral, passam a atribuir sentido a suas ações, face às diferentes atitudes e reflexões vivenciadas durante a sua trajetória de vida (BRITO, LIMA e LOPES, 2015).

Altarugio e Locatelli (2018) afirmam que apesar da legítima e fundamental preocupação dos cursos de formação inicial e continuada de professores em formar um bom docente, introduzindo em seus currículos conteúdos relacionados, sobretudo, ao saber e ao saber fazer dos docentes, muitos deles escapam aos formadores e outros nem sequer chegam a ser considerados como relevantes nesse processo.

Pereira (2001) alerta que, na busca incessante por novos conhecimentos e técnicas, os professores ficam presos aos modelos idealizados, reféns de um discurso que lhes ditam regras de "como ser um bom professor". Além disso, na expectativa de obterem resultados 
satisfatórios a partir da aplicação direta dos conhecimentos que recebem, os professores acabam não refletindo sobre esse processo (MRECH, 1999).

Pensar a formação do professor envolve capacitá-lo, dentre outros, à prática de lidar com o conflito resultante do confronto entre os diversos saberes provenientes de diferentes grupos sociais que frequentam a escola e com os saberes sistematizados existentes em dado momento histórico social e que a escola se propõe a transmitir. Assim, os professores devem estar habilitados a constatarem a importância de desenvolver uma prática pedagógica mais consistente, que esteja diretamente ligada à vida dos educandos (NUNES, 2001).

Conforme Pimenta (1999), ao contrário do que se necessita, os cursos de formação inicial, ao desenvolverem currículos formais com conteúdos e atividades distanciados na realidade e da verdadeira prática social de educar, pouco contribuem para formar uma nova identidade do profissional docente. Com referência à formação contínua, o que mais tem ocorrido é a realização de cursos de suplência e/ou atualização dos conteúdos de ensino, o que tem se mostrado pouco eficiente na modificação da prática, pelo fato de não considerarem a prática docente e pedagógica escolar em seus contextos.

Entende-se que o tipo de formação que o professor recebe, poderá vir a refletir de modo direto em suas ações pedagógicas, em sua forma de planejar e intervir no cotidiano escolar e, por consequência, na formação que será propiciada aos alunos (CORREIA, 2008).

Acerca da formação docente na universidade, assim se expressa Tardif (2002 p. 276): “[...] acreditamos que já é tempo de os professores universitários da educação começarem também a realizar pesquisas e reflexões críticas sobre suas próprias práticas de ensino." Falhas existentes fazem com que os questionamentos acerca dos fundamentos da prática pedagógica sejam evitados, principalmente no que se refere a postulados implícitos sobre a natureza dos saberes relativos ao ensino.

O conceito de saber docente é definido por Tardif (2002, p. 36) como um "saber plural, formado pelo amálgama, mais ou menos coerente, de saberes oriundos da formação profissional e de saberes disciplinares, curriculares e experienciais".

Para Gauthier (1998), a noção de saber foi definida a partir de três concepções diferentes que se referem a um lugar particular: a subjetividade, o juízo e a argumentação. Assim, o saber originário na subjetividade é todo tipo de certeza subjetiva produzida pelo pensamento racional, que se opõe à dúvida, ao erro e à imaginação e se diferencia, igualmente, dos outros tipos de certeza, como a fé e as ideias preconcebidas. 
Tardif (2010), afirma que o saber docente é um saber composto de vários saberes oriundos de fontes diferentes e produzidos em contextos institucionais e profissionais variados. Nesse mesmo prisma, Tardif, Lessard e Lahaye (1991) nos mostram que

a relação dos docentes com os saberes não se reduz a uma função de transmissão dos conhecimentos já constituídos, pois sua prática integra diferentes saberes, com os quais o corpo docente mantém diferentes relações. TARDIF, LESSARD e LAHAYE (1991, p. 218).

Saviani (1996, p. 147), ao se referir a esses saberes que configuram o trabalho do educador afirma que "o ato de produzir, direta e intencionalmente, em cada indivíduo singular, a humanidade que é produzida histórica e coletivamente pelo conjunto dos homens", constitui o trabalho educativo que é próprio do educador, afirma que sendo o processo educativo um fenômeno complexo, os saberes nele envolvidos também o são. Por conseguinte, o autor identifica cinco categorias de "saberes": o saber atitudinal, o saber crítico-contextual, os saberes específicos, o saber pedagógico e o saber didático curricular, entendendo que são esses os saberes que todo educador deve dominar e que, portanto, devem integrar o seu processo de formação.

Segundo Diniz-Pereira (2006) o professor durante a sua formação inicial, precisa compreender o próprio processo de construção e produção do conhecimento escolar, entender as diferenças e semelhanças dos processos de produção do saber científico e do saber escolar, conhecer as características da cultura escolar, saber a história da ciência e a história do ensino da ciência com que trabalha e em que pontos elas se relacionam.

Para Perrenoud (2001)

(...) é necessário que a formação inicial não possa ser percebida como uma lista de aquisições lineares, pois o ofício de professor compreende um conjunto de tarefas complexas e exige múltiplos saberes. (PERRENOUD, 2001, p.63).

Durante a formação inicial o licenciando/a vai construindo um conhecimento sobre o trabalho docente, temporal, plural, heterogêneo, personalizado e situado, que contribui para a construção da identidade profissional (PIMENTA; ANASTASIOU, 2002). No entanto, para ser professor, em síntese, é necessário um conjunto de saberes específicos que norteiam o trabalho do docente (GAUTHIER, 1998).

\section{Procedimentos Metodológicos}

\subsection{O CARÁTER QUALITATIVO DA PESQUISA}

A presente pesquisa foca no aspecto subjetivo dos atores envolvidos, portanto sendo esta de natureza qualitativa. Neves (2015) aponta que a pesquisa qualitativa tem o especial 
objetivo de revelar os mistérios que permeiam o cotidiano escolar, identificando processos que, muitas vezes, devido ao fato de se tornarem parte da rotina de uma determinada realidade escolar, passam despercebidos pelos próprios envolvidos na pesquisa.

No entender de Lima e Moreira (2015) a pesquisa qualitativa parte do pressuposto que existe uma relação dinâmica entre o mundo real e o sujeito, um vínculo indissociável entre o mundo objetivo e a subjetividade do sujeito. O objeto é sob essa perspectiva, essencialmente, qualitativo. Oliveira (2016, p.37) destaca como sendo “[...] um processo de reflexão e análise da realidade através da utilização de métodos e técnicas para compreensão detalhada do objeto de estudo em seu contexto histórico e/ou segundo sua estruturação [...]".

Dessa forma, entendemos que nessa pesquisa houve uma relação proximal entre os sujeitos envolvidos com o intuito de compreender a realidade que ali se apresentava.

\subsection{INSTRUMENTO DE COLETA DE DADOS: O QUESTIONÁRIO}

Para Oliveira (2016) os instrumentos para coleta de dados devem estar diretamente adequados aos objetivos da pesquisa. Por considerar que o ato da pesquisa é um ato criativo, não há um padrão determinado de técnicas a ser pesquisado, o pesquisador deve utilizar instrumentos que se adequem ao seu objeto de estudo e utilizar técnicas que captem a realidade a qual está inserido no contexto.

Para essa pesquisa utilizamos a coleta de dados através do uso de questionários com vinte (20) licenciandos matriculados desde o oitavo período até ao décimo, isto é, os concluintes do curso de Licenciatura em Ciências Biológicas (da Universidade do Estado do Amazonas) que já haviam estudado a disciplina de Estágio Curricular. Um questionário, segundo Gil (2009), é uma técnica de investigação com questões que possuem o propósito de obter informações. Nesse sentido, Parasuraman (1991) destaca que o questionário é um conjunto de questões feito com o fim de gerar os dados necessários para se atingirem os objetivos esperados. Embora não exista uma metodologia padrão, o questionário precisa ser formulado de modo a atender ao objetivo do trabalho.

A escolha de um instrumento de análise é uma das etapas mais importantes de um estudo, pois será esse instrumento que dará subsídios para a fidelidade da pesquisa. No entanto, essa escolha dependerá de fatores que servirão de base para a análise como o tipo da pesquisa e o material que será analisado.

Para isso nos apoiaremos em Laurence Bardin (2011) ao utilizar a Análise de Conteúdo para a reflexão dos dados obtidos. O termo análise de conteúdo designa um conjunto de técnicas 
de análise das comunicações visando obter, por procedimentos sistemáticos e objetivos de descrição do conteúdo das mensagens, indicadores (quantitativos ou não) que permitam a inferência de conhecimentos relativos às condições de produção/recepção (variáveis inferidas) destas mensagens.

Godoy (1995b), afirma que a análise de conteúdo, segundo a perspectiva de Bardin, consiste em uma técnica metodológica que se pode aplicar em discursos diversos e a todas as formas de comunicação, seja qual for à natureza do seu suporte. Segundo Câmara (2013), o pesquisador deve buscar compreender as características, estruturas ou modelos que estão por trás dos fragmentos de mensagens. O esforço do analista é, então, duplo: entender o sentido da comunicação, como se fosse o receptor normal, e, principalmente, desviar o olhar, buscando outra significação, outra mensagem, passível de se enxergar por meio ou ao lado da primeira.

Nesse sentido, Chizzotti (2006, p. 98), corrobora ao afirmar que "o objetivo da análise de conteúdo é compreender criticamente o sentido das comunicações, seu conteúdo manifesto ou latente, as significações explícitas ou ocultas."

Na perspectiva de Bardin (2011) utilizamos três segmentos cronológicos orientados pela Análise de Conteúdo: a Pré-Análise, A Exploração do Material e o Tratamento dos Resultados.

Para Câmara (2013) a primeira fase, a pré-análise, pode ser identificada como uma fase de organização. Nela estabelece-se um esquema de trabalho que deve ser preciso, com procedimentos bem definidos, embora flexíveis. Normalmente, segundo Bardin (2011), envolve a leitura "flutuante", ou seja, um primeiro contato com os documentos que serão submetidos à análise, a escolha deles, a formulação das hipóteses e objetivos, a elaboração dos indicadores que orientarão a interpretação e a preparação formal do material.

Para Maciel (2013) nesta fase da organização do trabalho deve-se estabelecer contato com os documentos deixando-nos invadir por impressões e orientações. Portanto, percebemos que, pouco a pouco, a leitura dos documentos vai tornando-se mais precisa, clara e concisa.

Segundo Campos (2004) deve-se empreender várias leituras de todo o material coletado, a princípio sem compromisso objetivo de sistematização, mas sim se tentando apreender de uma forma global as ideias principais e os seus significados gerais.

Ainda, segundo o autor supracitado, selecionado o corpus a ser analisado procede-se às leituras flutuantes de todo o material, com o intuito de apreender e organizar de forma não estruturada aspectos importantes para as próximas fases da análise. Nessa leitura toma-se contato com os documentos a serem analisados, conhece-se o contexto e deixa-se fluir impressões e orientações. 
Portanto, são empreendidas várias leituras de todo o material coletado, a princípio sem compromisso objetivo de sistematização, mas sim se tentando apreender de uma forma global as ideias principais e os seus significados gerais. Pode-se garantir que nesta fase da análise existe uma interação significativa do pesquisador com o material de análise, pois como um contato totalizante, muitas das impressões trabalhadas no contato direto com o sujeito afloram na lembrança e auxiliam na condução deste procedimento. Nesta fase a utilização de uma leitura menos aderente, promove uma melhor assimilação do material e elaborações mentais que forneceram indícios iniciais no caminho a uma apresentação mais sistematizada dos dados. Essas leituras iniciais promovem uma visão "descolada", a qual permite ao pesquisador transcender a mensagem explícita e de uma forma menos estruturada já conseguir visualizar mesmo que primariamente, pistas e indícios não óbvios (CAMPOS, 2004).

Na segunda fase, ou fase de exploração do material, são escolhidas as unidades de codificação, adotando-se os seguintes procedimentos de codificação [que compreende a escolha de unidades de registro - recorte; a seleção de regras de contagem - enumeração - e a escolha de categorias - classificação e agregação - rubricas ou classes que reúnem um grupo de elementos (unidades de registro) em razão de características comuns], classificação [semântico (temas, no exemplo dado), sintático, léxico - agrupar pelo sentido das palavras; expressivo agrupar as perturbações da linguagem tais como perplexidade, hesitação, embaraço, outras, da escrita, etc...] e categorização (CÂMARA, 2013).

Com a unidade de codificação escolhida, o próximo passo será a classificação em blocos que expressem determinadas categorias (no questionário aplicado aos alunos, retirou-se apenas as falas que se referiam ao objeto investigado). Assim, num movimento contínuo da teoria para os dados e vice-versa, as categorias vão se tornando cada vez mais claras e apropriadas aos propósitos do estudo (CÂMARA, 2013).

Segundo Campos (2004) pode-se caracterizar as categorias como grandes enunciados que abarcam um número variável de temas, segundo seu grau de intimidade ou proximidade, e que possam através de sua análise, exprimirem significados e elaborações importantes que atendam aos objetivos de estudo e criem novos conhecimentos, proporcionando uma visão diferenciada sobre os temas propostos.

A terceira fase do processo de análise do conteúdo é denominada tratamento dos resultados - a inferência e interpretação. Segundo Bardin (2011) a inferência na análise de conteúdo se orienta por diversos polos de atenção, que são os polos de atração da comunicação. 
É um instrumento de indução (o questionário aplicado) para se investigarem as causas (variáveis inferidas) a partir dos efeitos (variáveis de inferência ou indicadores, referências),

As interpretações a que levam as inferências serão sempre no sentido de buscar o que se esconde sob a aparente realidade, o que significa verdadeiramente o discurso enunciado, o que querem dizer, em profundidade, certas afirmações, aparentemente superficiais.

\section{Resultados e Discussão}

A seguir, apresentaremos e discutiremos os relatos encontrados nos questionários dos licenciandos do curso de Ciências Biológicas. Para isso, utilizaremos trechos das falas que mostram indícios da produção dos saberes docente a partir das categorias que emergiram na análise dos dados.

\subsection{Categoria 1: Afinidade no Ensino Médio}

Nessa categoria, podemos encontrar nas falas dos licenciandos o que Tardif (2010) chama de saberes profissionais. Para o autor é o conjunto de saberes transmitidos pelas instituições de formação de professores (escolas normais ou faculdades).

Pode-se observar que os licenciandos entrevistados, ingressaram na docência pela admiração por seus professores, o modo como eles transmitiam o conteúdo. Como pode ser observado nas falas a seguir:

Escolhi o curso de Ciências Biológicas pois sempre tive amor pela disciplina de biologia durante o ensino médio. Os professores me motivaram também a escolher esse curso por conta de sua didática. (A1).

...a escolha do curso em licenciatura foi motivada por admirar minha professora no ensino médio, que mesmo sem recursos e em uma escola totalmente abandonada pelo governo do estado, se dedicava e fazia toda a diferença na vida dos alunos. (A2).

...desde criança gostava de Ciências e dos animais...também fui motivada pela minha professora de Biologia que era muito boa nas aulas.... (A3).

Porque foi a disciplina que mais me identifiquei no ensino médio, por conta do professor dar uma boa aula. (A20).

A escola, a professora da educação básica, tem um papel fundamental na vida do sujeito em formação, pois o encantamento, a magia, as descobertas irão compor o processo formativo do indivíduo. A construção dessa identidade não ocorre em um momento específico, ela é mediada pelos conhecimentos pessoais, culturais e emocionais que os licenciandos trazem consigo e pelas experiências vivenciadas como aluno. Dessa forma, se faz necessário entender a formação do professor para a prática educativa para que se busque a profissionalização do mesmo (DASSOLER; LIMA, 2012). 
Nesse sentido, Tardif (2002) apontou para uma formação embasada na pluralidade dos diversos saberes que constituem os saberes profissionais, do currículo e do seu cotidiano. Mizukami (2006) sinaliza a necessidade dos professores perceberem a relação entre o desenvolvimento pessoal e profissional para facilitar a aprendizagem de seus docentes em formação.

\subsection{CATEgoria 2: EXPERIÊNCIA DOCENTE}

Pode-se observar na fala dos futuros professores, a relevância dos programas, tais como o Programa Institucional de Bolsa de Iniciação à Docência (PIBID) onde ocorre a inserção dos alunos cada vez mais cedo nas escolas, proporcionando um espaço de troca de conhecimentos e experiências. Pimenta (2005) denomina que os saberes da experiência se referem às experiências acumuladas ao longo do processo formativo e que podem influenciar a prática docente. Com relação aos saberes da docência referente ao conhecimento relaciona estes aos conhecimentos adquiridos durante a formação inicial e ao papel do conhecimento na sociedade. Observamos isso na fala dos seguintes alunos:

Participei do PIBID durante 2 anos, o que me fez aprender muito novos métodos, práticas e ajudou-me a desenvolver cada vez mais a criatividade para buscar elaborar uma aula cada vez melhor (A15).

O PIBID me ajudou bastante, além de um estágio no EJA que mudaram minha visão e me forneceram subsídios para ser um professor em sala (A17).

A iniciação à docência junto com o estágio da universidade me ajudou a ter mais experiência, como a relação professor aluno, tendo mais coragem para enfrentar as dificuldades em sala de aula (A1).

Segundo Tardif (2007), o futuro professor ao desenvolver atividades na escola, pode em sua trajetória pré-profissional construir uma socialização escolar e desta forma, ir edificando uma importante compreensão da natureza dos saberes requeridos ao professor. Saberes estes mobilizados e utilizados em sua carreira como também na socialização profissional e no próprio exercício do magistério. Saberes que podem ser tencionados para uma percepção ampla da profissão docente no sentido que "engloba os conhecimentos, as competências, as habilidades (ou aptidões) e as atitudes" (TARDIF, 2007, p. 255) e não apenas na discussão dos conteúdos a serem trabalhados na escola.

\subsection{Categoria 3: Identidade Profissional}

Perguntamos aos licenciandos se eles se identificam como um futuro professor de Biologia e no momento, dizem estar satisfeitos com a profissão que escolheram para exercer como podemos verificar nas falas a seguir: 
Com certeza...o motivo de escolher o curso foi justamente para fazer a diferença na educação básica de escolas públicas (A2).

Porque é o que realmente me fascina, e acho necessário que os alunos recebam aulas com conteúdos atualizados e com formas diferentes de ensinar, trazendo cada vez mais inovações que facilitem o processo de ensino e aprendizagem (A15)

Acredito que aplicarei os conhecimentos adquiridos durante a graduação da melhor forma possível (A20)

É um sonho e estou muito ansioso para começar (A17)

Para Gauthier (1998), embora antigo, o ofício de professor continua a ser cada vez mais necessário à sociedade. No entanto, de acordo com ele mal conseguimos identificar os atos do professor que, na sala de aula, têm influência concreta sobre a aprendizagem dos alunos, e estamos apenas começando a compreender como se dá a interação entre educador e educandos".

Concordamos com Pimenta (1997) quando fala que:

Uma identidade profissional se constrói, pois, a partir da significação social da profissão; da revisão constante dos significados sociais da profissão; da revisão das tradições. Como, também, da reafirmação de práticas consagradas culturalmente e que permanecem significativas. Práticas que resistem a inovações, porque estão prenhes de saberes válidos às necessidades da realidade. Do confronto entre as teorias e as práticas, da análise sistemática das práticas à luz das teorias existentes, da construção de novas teorias, constrói-se, também, pelo significado que cada professor, enquanto ator e autor, confere à atividade docente no seu cotidiano a partir de seus valores, de seu modo de situar-se no mundo, de sua história de vida, de suas representações, de seus saberes, de suas angústias e anseios, do sentido que tem em sua vida: o ser professor. (PIMENTA, 1997, p. 7).

Guimarães (2004) destaca que os cursos de formação inicial podem ter importante papel na construção ou fortalecimento da identidade docente, ao possibilitarem a reflexão e a análise crítica das representações sociais historicamente construídas e praticadas na profissão.

\section{CONSIDERAÇÕES FinaIS}

É notório que a constituição dos saberes docentes possuem origens distintas, durante a vida escolar inicial ou por diversos meios. A construção do conhecimento é o resultado do conjunto de etapas, que se dá a todo momento. Durante a vida escolar, os alunos adquirem experiências que fazem com que se identifiquem com determinadas situações, colegas e professores.

O resultado da pesquisa indica nas falas dos discentes a presença da identidade docente, os saberes experienciais e o processo de formação profissional. É notório que o processo de construção da identidade docente está baseado nas diferentes identidades dos professores que encontramos ao longo de nossa trajetória escolar. 
Nesse sentido, percebemos que na maioria das vezes, o gostar de ser professor, vem acompanhando a formação do indivíduo, ao logo do seu processo formativo e que se fortalece ao entrar em contato com o ofício de ser professor.

\section{REFERÊNCIAS}

ALTARUGIO, Maisa Helena; LOCATELLI, Solange Wagner. Os saberes docentes e a formação do bom professor de ciências. Revista Espaço Pedagógico, Passo Fundo, v. 25, n. 2, 2018. 364-382. Disponível em www.upf.br/seer/index.php/rep. Acesso de 13 de jul 2019.

ALTET, Marguerite. As Competências do Professor Profissional: entre Conhecimentos, Esquemas de Ação e Adaptação, Saber Analisar. In: PERRENOUD, Philippe et al. (Orgs). Formando Professores Profissionais. Porto Alegre: Artmed, 2001. p. 23-35.

BARDIN, Laurence. Análise de Conteúdo. 3a . Ed. Lisboa, Portugal; Edições 70, 2011.

BRITO, Assicleide da Silva; LIMA, Maria Batista; LOPES, Edinéia Tavares. Reflexões sobre os saberes docentes e a formação de professores de química. Revista fórum identidades, Itabaiana, Ano 9, v.18, 2015. Disponível em:

https://seer.ufs.br/index.php/forumidentidades/article/viewFile/4757/3978. Acesso em $22 \mathrm{de}$ jun 2019.

BRITO, Antonia Edna. Professores experientes e formação profissional:

evocações...narrativas...e trajetórias. Revista Linguagens, Educação e Sociedade, Teresina, v. 12, n. 17, 2007. 29-38. Disponível em:

http://leg.ufpi.br/subsiteFiles/ppged/arquivos/files/Revista/N17/art_3.pdf. Acesso em 23 de maio 2019.

CÂMARA, Rosana Hoffman. Análise de conteúdo: da teoria à prática em pesquisas sociais aplicadas às organizações. Gerais: Revista Interinstitucional de Psicologia, São Paulo, v. 6, n.2, 2013, 179-191. Disponível em: http://pepsic.bvsalud.org/pdf/gerais/v6n2/v6n2a03.pdf. Acesso em: 18 de set. 2019.

CARVALHO, Ana Maria. Pessoa de.; GIL-PÉREZ, Daniel. Formação de professores de Ciências. $2^{a}$. ed. São Paulo: Cortez, 1995.

CAMPOS, Claudinei José Gomes. MÉTODO DE ANÁLISE DE CONTEÚDO: ferramenta para a análise de dados qualitativos no campo da saúde. Rev Bras Enferm, Brasília, 2004 v. 57, n. 5, 2004, 611-614. Disponível em: http://www.scielo.br/pdf/reben/v57n5/a19v57n5.pdf. Acesso em: 15 de set de 2019.

CORREIA, Marinêz Luiza. A formação inicial do professor: os desafios e tensões que a prática pedagógica impõe. ANALECTA Guarapuava, Paraná v.9 n. 2, 2008. 11-20. Disponível em: https://revistas.unicentro.br/index.php/analecta/article/viewFile/1717/1546. Acesso 04 de maio 2019.

CHIZZOTTI, Antonio. Pesquisa em ciências humanas e sociais. $8^{\mathrm{a}}$ ed, São Paulo, Cortez. 2006. 
DASSOLER, Olmira Bernadete; LIMA, Denise Maria Soares. A formação e a profissionalização docente: características, ousadia e saberes. In: IX Seminário ANPED SUL, 2012, Anais eletrônicos do IX ANPED SUL, Caxias do Sul: UCS, 2012. Disponível em:http://www.ucs.br/etc/conferencias/index.php/anpedsul/9anpedsul/paper/viewFile/3171/52 2. Acesso em 11 de maio 2019.

DEMO, Pedro. Educar pela pesquisa. Campinas, $1^{\text {a }}$. ed. Autores associados, 1998.

DINIZ-PEREIRA, Júlio Emílio. Debates e pesquisas no Brasil sobre a formação docente. In: PEREIRA, Júlio Emílio Diniz. Formação de professores: pesquisas, representações e poder. Belo Horizonte: Autêntica, 2006. p. 115-135.

GARIGLIO, José Ângelo.; BURNIER, Suzana Lana. Os professores da educação profissional: saberes e práticas. Cadernos de Pesquisa, São Paulo, v. 44, n. 154. 2014. 02-26. Disponível em: http://www.scielo.br/pdf/cp/v44n154/1980-5314-cp-44-154-00934.pdf. Acesso em 13 de jun 2019.

GAUTHIER, Clermont. Por uma teoria da Pedagogia. 4ª ed. Ijuí, RS: Editora Unijuí, 2013.

GAUTHIER, Clemont. Por uma teoria da pedagogia: Pesquisas contemporâneas sobre o saber docente. $1^{\text {a }}$. ed. Ijuí: Editora Unijuí, 1998.

GIL, Antônio Carlos. Métodos e técnicas de pesquisa social. $6^{\text {a }}$ ed. São Paulo: Atlas, 2009.

GODOY, Arilda Schmidt. Pesquisa qualitativa: tipos fundamentais. Revista de Administração de Empresas, São Paulo, v. 35, n. 4, 1995b, 65-71. Disponível em: http://www.scielo.br/scielo.php?script=sci_arttext\&pid=S0034-75901995000300004. Acesso em: 20 de set. 2019.

GUIMARÃES, Valter Soares. Formação de professores: saberes, identidade e profissão. $1^{\text {a }}$. ed. Campinas: Papirus, 2004.

IMBERNÓN, Francisco. Formação continuada de professores. $1^{\mathrm{a}}$. ed. Porto Alegre: Artmed, 2010.

LIMA, Maria do Socorro Bezerra; MOREIRA, Érika Vanessa. A pesquisa qualitativa em Geografia. Caderno Prudentino de Geografia. Presidente Prudente, v.2, n.37, 2015, 27-55. Disponível em: http://revista.fct.unesp.br/index.php/cpg/article/viewFile/4708/3618. Acesso em 19 de set 2019.

MACIEL, Hiléia Monteiro. O potencial pedagógico dos espaços não formais da cidade de Manaus, 2013. 120f. Manaus: Dissertação (Mestrado Acadêmico em Educação em Ciências na Amazônia) Universidade do Estado do Amazonas, Manaus, 2013. Disponível em:

http://www.pos.uea.edu.br/data/area/titulado/download/38-8.pdf . Acesso em 22 maio 2019.

MALDANER, Otavio Aloisio. A formação inicial e continuada de professores de Química: professores/pesquisadores. 1ª . ed. Ijuí: Editora Unijuí, 2006.

MIZUKAMI, Maria da Graça Nicoletti. Aprendizagem da docência: professores formadores. Revista E-Curriculum, São Paulo, v. 1, n. 1, dez/jul. 2005-2006, 1 - 17. Disponível em: 
http://revistas.pucsp.br/index.php/curriculum/article/viewFile/3106/2046. Acesso em 22 de maio 2019.

MRECH, Leny Magalhães. Psicanálise e educação: novos operadores de leitura. $1^{a}$. ed. São Paulo: Pioneira, 1999.

NEVES, Miranilde Oliveira. A importância da investigação qualitativa no processo de formação continuada de professores: subsídios ao exercício da docência Revista

Fundamentos, Piauí v.2, n.1, 2015. 17-31. Disponível em:

http://www.ojs.ufpi.br/index.php/fundamentos/article/download/3723/2186. Acesso em: 19 de set 2019.

NÓVOA, Antônio. Formação de professores e profissão docente. $1^{\text {a }}$. ed. Lisboa: Dom Quixote, 1992.

NUNES, Célia Maria Fernandes. Saberes docentes e formação de professores: um breve panorama da pesquisa brasileira. Educação \& Sociedade, ano XXII, n. 74, abr/2001. 27-42. Disponível em: http://www.scielo.br/pdf/es/v22n74/a03v2274.pdf. Acesso em 17 de ago 2019.

OLIVEIRA, Maria Marly de. Como fazer pesquisa qualitativa. 7 ed. Vozes, Petrópolis - RJ, 2016.

PARASURAMAN, August. Marketing research, $2^{\mathrm{a}}$ ed. New York: Addison-Wesley Publishing Company, 1991.

PEREIRA, Marcelo. $\mathbf{O}$ relacional e o seu avesso na ação do bom professor. In: LOPES, Eliane M. T. (Org.). A psicanálise escuta a educação. Belo Horizonte: Autêntica, 2001.

PERRENOUD, Philippe. Formando professores profissionais: quais estratégias? Quais competências? 1 ${ }^{\mathrm{a}}$. ed. Porto Alegre: Artmed, 2001.

PIMENTA, Selma Garrido. Saberes pedagógicos e atividade docente. $1^{\mathrm{a}}$. ed. São Paulo: Cortez, 2005.

PIMENTA, Selam Garrido. Formação de professores: saberes da docência e identidade do professor. Nuances, Presidente Prudente, v. 3, n.2, 1997. 5-14. Disponível em:

https://edisciplinas.usp.br/mod/resource/view.php?id=638933. Acesso em 12 de jul 2019.

PIMENTA, Selma . Garrido.; ANASTASIOU, Léa das Graças Camargos. Docência no ensino superior. $1^{a}$. ed. São Paulo: Cortez, 2002. .

PIMENTA, Selma Garrido. Formação de Professores: identidade e saberes da docência. In: PIMENTA, S. G. (org). Saberes Pedagógicos e Atividade Docente. São Paulo: Cortez, 1999. p. 15-34.

PIMENTA, Selam Garrido.; LIMA, Maria Socorro Lucena. Estágio e docência. 1ª. ed. São Paulo: Editora Cortez, 2004.

PORLÁN, Rafael.; RIVERO, Ariza. El conocimiento de los profesores. $1^{a}$. ed. Sevilla: Diada, 1998. 
ROSA, Maria Inês Petrucci. Investigação e ensino: articulações e possibilidades na formação de professores de Ciências. 1ª . ed. Unijuí, 2004.

SAVIANI, Dermeval. Educação: Do Senso Comum à Consciência Filosófica. $1^{\text {a }}$. ed. Campinas, SP: Autores Associados, 1996.

SEVERINO, Antônio Joaquim. Ensino e pesquisa na docência universitária: caminhos para a integração. In: ALMEIDA, Maria Isabel de; PIMENTA, Selma Garrido. (Org.). Pedagogia Universitária. São Paulo: EDUSP, 2009. p. 01-40.

SCHNETZLER, Roseli. O professor de Ciências: problemas e tendências de sua formação. In: SCHNETZLER, R. P.; ARAGÃO, R. M. R. (Org.). Ensino de Ciências; fundamentos e abordagens. Campinas, R. Vieira Gráfica Editora, 2000. p. 120-153.

TARDIF, Maurice. Saberes docentes e formação profissional. $5^{\text {a }}$. ed. Petrópolis, RJ: Vozes, 2014.

TARDIF, Maurice. Saberes docentes e formação profissional. 1 $^{\mathrm{a}}$. ed. Editora Vozes, Petrópolis, 2002.

TARDIF, Maurice. Saberes docentes e formação profissional. 2a . ed. Editora Vozes, Petrópolis, 2007.

TARDIF, Maurice. Saberes docentes e formação profissional. $4^{\mathrm{a}}$. ed. Petrópolis, RJ: Vozes, 2010.

TARDIF, Maurice; LESSARD, Claude; LAHAYE, Louise. Os professores face ao saber esboço de uma problemática do saber docente. Teoria e Educação, Porto Alegre, v.2, n. 4, 1991. 215-233.Disponível em:

https://edisciplinas.usp.br/pluginfile.php/4118869/mod_resource/content/1/TARDIF\%2C\%20 Maurice\%20et\%20al.\%200s\%20professores\%20face\%20ao\%20saber\%20\%20esbo\%C3\%A7o\%20de\%20uma\%20problem\%C3\%A1tica\%20do\%20saber\%20docente.p df. Acesso em: 17 de ago 2019.

ZEICHNER, Kenneth. A Enseñanza reflexiva y experiencias de aula en la formación del profesorado. Revista de Educación, Espanha, v. 5, n. 282, 1987. 161-189. Disponível em: https://dialnet.unirioja.es/ejemplar/1974. Acesso em 15 de jun 2019.

Recebido em: 18 de agosto de 2019. Aprovado em: 18 de dezembro de 2019. 